\title{
KARAKTERISTIK ANSIETAS PADA PASIEN EPILEPSI DI AMBON
}

\author{
Ivanmorl Ruspanah \\ Fakultas Kedokteran Universitas Pattimura \\ Corresponding author e-mail : ivanmorl86@gmail.com
}

\begin{abstract}
Abstrak
Pendahuluan. Epilepsi merupakan suatu manifestasi gangguan otak dengan berbagai macam penyebab, terjadi pada semua umur, ras, dan kelas sosial serta memiliki gangguan penyerta lainnya seperti gangguan ansietas. Tujuan. Tujuan dari penelitian ini untuk mengetahui karakteristik ansietas pada pasien epilepsi di Ambon. Metode. Jenis penelitian deskriptif dengan pendekatan cross sectional. Subyek penelitian adalah pasien epilepsi primer yang berobat ke Poliklinik Saraf RSUD dr. M. Haulussy Ambon, RSKD Provinsi Maluku dan di dua Klinik Dokter Spesialis Saraf di Ambon selama periode Juli sampai Oktober 2013. Data didapat melalui wawancara terpimpin dengan panduan kuisioner. Hasil. Dari 42 responden yang diteliti, ditemukan 9 responden $(21,4 \%)$ yang mengalami ansietas dengan derajat ansietas yang banyak ditemukan adalah ansietas derajat ringan (11,8\%). Ansietas terbanyak pada epilepsi tipe parsial yaitu 7 responden $(16,6 \%)$ dan terbanyak pada usia 17 - 25 tahun yaitu 5 responden $(11,8 \%)$; ansietas juga terbanyak pada perempuan yaitu 6 responden (14,2\%); berdasarkan tingkat pendidikan, ansietas terbanyak pada lulusan SMA (14,2\%); ansietas sebesar 16,6\% pada kelompok yang tidak bekerja. Kesimpulan. Pada penelitian ini menunjukan bahwa pasien epilepsi yang berisiko mengalami ansietas yaitu penderita epilepsi tipe parsial dengan jenis kelamin perempuan, berusia remaja dan lulusan tingkat menengah serta tidak memiliki pekerjaan. Oleh sebab itu selain diberi terapi farmakologi, perlu dilakukan pencegahan berupa edukasi baik terhadap pasien epilepsi maupun keluarga dan masyarakat sekitar sehingga dapat terhindar dari ansietas.
\end{abstract}

Kata kunci : epilepsi, ansietas.

\begin{abstract}
Introduction. Epilepsy is a brain disorder is manifested WITH Jazz RS causes, occur at any age, race, and social class as well as having other concomitant Disorders such as Anxiety disorders. Aim. Purpose of the research is for the review to know the characteristics of anxiety on epilepsy patients in Ambon. Methods. the research was using descriptive and cross sectional study. The subject of research was the primary epilepsy patient medication into the neural polyclinic dr. M. Haulussy Ambon, Maluku Province and RSKD Nerve Specialist Clinic in Ambon during the period from July to October 2013. Data were obtained through interviews guided with questionnaire. Result. Of 42 respondents, founded nine respondents (21.4\%) with anxiety. The degree of anxiety experienced anxiety was light enxiety (11.8\%). Anxiety Most types of partial epilepsy on 7 respondents (16.6\%) and the highest were 17-25 years old (11.8\%); Also anxiety most on women (14.2\%); by Level of Education, the highest anxiety were High school graduates (14.2\%); and 16.6\% were jobless. Conclusion. The research concludes that patients with epilepsy sufferers Gender Woman, teens and graduates Intermediate and not having a job. Therefore, given the besides pharmacological therapy, should be done prevention of patients with epilepsy or family community and neighborhoods that can be spared from anxiety.
\end{abstract}

Key words : epilepsy, anxiety. 


\section{Pendahuluan}

Pasien dengan epilepsi biasanya memiliki kondisi psikiatri penyerta yang meliputi gangguan ansietas, gangguan mood, dan gangguan psikotik. Ada hubungan dua arah antara epilepsi dan gangguan psikiatrik yang digambarkan sebagai epifenomena daripada faktor sebab-akibat. Dari antara komorbiditas psikiatrik, gangguan ansietas memiliki frekuensi yang tinggi dan pengaruh yang sangat besar pada kualitas hidup pasien epilepsi terkait kesehatan.

Terjadinya perubahan perilaku pada epilepsi dapat disebabkan oleh epilepsinya sendiri, maupun faktor lain misalnya obat antiepilepsi, penyakit otak yang mendasarinya, reaksi atau tanggapan personal terhadap epilepsi, dan idiopatik. Dari hasil penelitian di Rumah Sakit Umum Daerah dr. Moewardi Surakarta Tahun 2012 yang dilakukan oleh Lusia, terdapat hubungan antara ansietas dan frekuensi bangkitan penderita epilepsi khususnya epilepsi parsial. Usia dan jenis kelamin memiliki pengaruh yang relatif tajam. Ansietas yang diderita oleh wanita penderita epilepsi lebih besar daripada pria. Risiko gangguan ansietas tampak lebih tinggi pada epilepsi fokal (lobus temporal) daripada epilepsi umum, tetapi juga terlihat pada epilepsi lobus frontal maupun kejang umum dan primer.

Data mengenai proporsi dan derajat ansietas pada pasien epilepsi masih kurang, khususnya di Ambon, maka perlu untuk dilakukan penelitan mengenai karakteristik ansietas pada pasien epilepsi.

\section{Metode}

Penelitian ini merupakan penelitian deskriptif dengan pendekatan cross sectional. Penelitian dilaksanakan di Poliklinik Saraf Rumah Sakit Umum Daerah dr. M. Haulussy dan Rumah Sakit Khusus Daerah Provinsi Maluku serta dua Klinik Dokter Spesialis Saraf yaitu Klinik Mardika dan Klinik Cahaya Farma di Ambon selama periode Juli Oktober 2013.

Pasien yang memenuhi kriteria
inklusi, diberikan penjelasan, diminta
persetujuan mengikuti penelitian dan mengisi
informed consent. Setelah pasien setuju untuk
mengikuti penelitian, pasien mengisi
kuesioner HARS. kemudian mengelompokan
data sesuai karaketristik pasien epilepsi
tersebut. Setelah dilakukan pengelompokan
data, maka data akan ditabulasi dan dianalisis
secara deskriptif.

\section{Hasil}

Selama periode tersebut, jumlah pasien epilepsi primer yang datang berobat sebanyak 47 responden tetapi di antaranya ada 5 responden yang dieksklusi dari penelitian dan hanya ada 42 responden yang memenuhi kriteria inklusi.

http://ojs3.unpatti.ac.id/index.php/moluccamed 
Tabel 1. Kriteria Ekslusi Pasien

\begin{tabular}{|l|c|}
\hline \multicolumn{1}{|c|}{ Kriteria eksklusi } & Jumlah \\
\hline Gangguan kognitif sedang hingga berat & 2 \\
(MMSE $\leq 20)$ & 3 \\
Tidak tamat Sekolah Dasar & 5 \\
\hline \multicolumn{1}{|c|}{ Total } & \\
\hline
\end{tabular}

Dengan demikian, sampel yang diteliti

(n) sebanyak 42 responden (dengan respond rate $=89,36 \%$ ) yaitu responden yang memenuhi kriteria inklusi dengan karakteristik responden.

Tabel 2. Karateristik Responden

\begin{tabular}{|l|r|}
\hline \multicolumn{1}{|c|}{$\begin{array}{c}\text { Karakteristik } \\
\text { Responden }\end{array}$} & $\mathrm{n}(\%)$ \\
\hline Tipe Epilepsi & \\
- Umum & $34(80,95)$ \\
- Parsial & $8(19,05)$ \\
\hline Usia & $12(28,6)$ \\
$-12-16$ th & $21(50)$ \\
$-17-25$ th & $3(7,1)$ \\
- 26-35 th & $4(9,5)$ \\
- 36-45 th & $2(4,8)$ \\
- 46-55 th & $24(57,1)$ \\
\hline Jenis Kelamin & $18(42,9)$ \\
- Perempuan & \\
- Laki-laki & $9(21,4)$ \\
\hline Pendidikan & $9(21,4)$ \\
- SD & $20(47,6)$ \\
- SMP & $2(4,8)$ \\
- SMA & $2(4,8)$ \\
- Sarjana & \\
- Diploma & $34(80,95)$ \\
\hline Pekerjaan & $8(19,05)$ \\
- Tidak bekerja & jumlah \\
- Bekerja & \\
nilai \% dihitung & berdasarkan \\
responden &
\end{tabular}

Dari hasil penelitian pada 42 responden berdasarkan tipe epilepsi didapatkan data 34 responden $(80,95 \%)$ epilepsi umum dan 8 responden $(19,05 \%)$ epilepsi parsial. Berdasarkan usia didapatkan data responden terbanyak pada usia $17-25$ tahun yaitu sebanyak 21 responden (50\%) dan terendah pada usia 46 - 55 tahun yaitu 2 responden $(4,8 \%)$. Berdasarkan jenis kelamin didapatkan data responden perempuan sebanyak 24 orang $(57,1 \%)$ dan laki-laki sebanyak 18 orang $(42,9)$.

Berdasarkan tingkat pendidikan terakhir didapatkan data yang sama pada lulusan SD dan SMP yaitu 9 responden $(21,4 \%)$, lulusan SMA yaitu 20 responden $(47,6 \%)$, dan jumlah yang sama pada lulusan Sarjana dan Diploma yaitu 2 responden $(4,8 \%)$. Berdasarkan pekerjaan didapatkan data 34 responden $(80,95 \%)$ tidak bekerja, 8 responden $(19,05 \%)$ bekerja.

Proporsi Komorbiditas Ansietas Pada Pasien Epilepsi Primer

Dari hasil penelitian diketahui bahwa proporsi komorbiditas ansietas sebesar 21,4\% dari 42 orang yang menderita epilepsi seperti yang terlihat pada tabel di bawah ini. 
Tabel 3. Proporsi Komorbiditas Ansietas Pada Pasien Epilepsi Primer

\begin{tabular}{|c|c|c|}
\hline $\begin{array}{c}\text { Epilepsi } \\
\text { primer } \\
\text { Tidak ansietas }\end{array}$ & $\begin{array}{c}\text { Skor } \\
\text { ansietas }\end{array}$ & $\mathrm{n}(\%)$ \\
Ansietas & $\geq 14$ & $33(78,6)$ \\
\hline Total & & $42(100)$ \\
\hline
\end{tabular}

Hasil penelitian sebelumnya yang dilakukan di Rumah Sakit Umum Pusat Haji Adam Malik Medan pada Tahun 2005 oleh Iqbal KM et al, didapatkan frekuensi ansietas 4,8\% dari 42 penderita epilepsi.

Derajat Komorbiditas Ansietas Pada Pasien Epilepsi Primer

Sesuai dengan tabel 4 didapatkan 9 responden $(21,4 \%)$ menderita ansietas. Dari 9 responden $(21,4 \%)$ ini ditemukan derajat ansietas yang terbanyak adalah derajat ringan sebanyak 5 responden $(11,8 \%)$.

Tabel 4. Derajat Komorbiditas Ansietas Pada Pasien Epilepsi Primer

\begin{tabular}{|c|c|c|}
\hline $\begin{array}{c}\text { Derajat } \\
\text { ansietas } \\
\text { Tidak ansietas }\end{array}$ & $\begin{array}{c}\text { Skor } \\
\text { ansietas }\end{array}$ & $\mathrm{n}(\%)$ \\
Ringan & $14-20$ & $5(11,8)$ \\
Sedang & $21-27$ & $2(4,8)$ \\
Berat & $28-41$ & $2(4,8)$ \\
Berat sekali & $42-56$ & $0(0)$ \\
\hline Total & & $42(100)$ \\
\hline Karakteristik & Responden & Berdasarkan
\end{tabular}

Komorbiditas Ansietas
Tabel 5. Karakteristik Responden Bedasarkan Komorbiditas Ansietas

\begin{tabular}{|c|c|c|}
\hline $\begin{array}{c}\text { Karakteristik } \\
\text { Responden }\end{array}$ & $\begin{array}{c}\text { Tidak } \\
\text { Ansietas } \\
\mathrm{n}(\%)\end{array}$ & $\begin{array}{c}\text { Ansietas } \\
\mathrm{n}(\%)\end{array}$ \\
\hline $\begin{array}{c}\text { Tipe Epilepsi } \\
\text { - Umum }\end{array}$ & $32(76,2)$ & $2(4,8)$ \\
- Parsial & $1(2,4)$ & $7(16,6)$ \\
\hline Usia & & \\
- 12-16 th & $11(26,2)$ & $1(2,4)$ \\
- 17-25 th & $16(38,1)$ & $5(11,8)$ \\
- 26-35 th & $2(4,8)$ & $1(2,4)$ \\
- 36-45 th & $3(7,1)$ & $1(2,4)$ \\
- 46-55 th & $1(2,4)$ & $1(2,4)$ \\
\hline Jenis Kelamin & & \\
- Perempuan & $18(42,9)$ & $6(14,2)$ \\
- Laki-laki & $15(35,7)$ & $3(7,2)$ \\
\hline Pendidikan & & \\
- SD & $9(21,4)$ & $0(0)$ \\
- SMP & $7(16,6)$ & $2(4,8)$ \\
- SMA & $14(33,4)$ & $6(14,2)$ \\
- Sarjana & $2(4,8)$ & $0(0)$ \\
- Diploma & $1(2,4)$ & $1(2,4)$ \\
\hline Pekerjaan & & \\
- Tidak bekerja & $27(64,3)$ & $7(16,6)$ \\
- Bekerja & $6(14,3)$ & $2(4,8)$ \\
\hline
\end{tabular}

nilai \% dihitung berdasarkan jumlah responden.

\section{Pembahasan}

Proporsi Komorbiditas Ansietas Pada Pasien Epilepsi Primer

Kurangnya pengertian tentang epilepsi oleh penderita dan keluarga serta masyarakat merupakan sebab utama terjadinya psikopatologi pada penderita epilepsi. Selain stigma tentang epilepsi, derajat keparahan bangkitan, durasi epilepsi dan politerapi juga merupakan faktor terkait epilepsi yang berhubungan dengan gejala ansietas. Peningkatan risiko ini dapat terjadi sebagai 
efek samping dari obat anti-epilepsi atau sebagai komplikasi yang berkaitan dengan obat anti-epilepsi. Risiko tampak lebih tinggi pada politerapi dibandingkan monoterapi.

Derajat Komorbiditas Ansietas Pada Pasien Epilepsi Primer

Hal serupa didapatkan pada penelitian sebelumnya yang dilakukan di Amerika pada Tahun 2005 oleh Cramer et al, ditemukan derajat ansietas terbanyak pada pasien epilepsi yaitu ansietas derajat ringan sebesar $25 \%$. Berbeda dengan penelitian yang dilakukan di Gaza pada Tahun 2013 oleh Ghaith, ditemukan derajat ansietas terbanyak yaitu ansietas derajat sedang sebesar $47,9 \%$.

Pasien dengan epilepsi yang mengalami skor ansietas lebih tinggi secara signifikan berhubungan dengan frekuensi kejang yang lebih tinggi dan kurangnya pengobatan, sehingga ada hubungan antara frekuensi kejang dan derajat ansietas. Frekuensi bangkitan yang rendah (1-5 kali setahun) akan menurunkan derajat ansietas terhadap kemungkinan terjadinya hal-hal yang dapat mencelakakan keselamatan jiwa, dibandingkan dengan frekuensi bangkitan yang tinggi. Derajat ansietas juga dapat diperberat oleh penyakit-penyakit lain yang menyebabkan epilepsi. Pada penelitian menunjukan derajat ansietas ringan, hal ini menunjukan bahwa pasien-pasien epilepsi yang diteliti telah memiliki pengobatan dari dokter yang memungkinkan frekuensi kejang dapat dikendalikan. Selain itu penelitian menggunakan pasien epilepsi primer yang tidak diketahui penyebabnya sehingga pasien terhindar dari penyakit-penyakit yang dapat memperburuk keadaan pasien yang akibatnya meningkatkan derajat ansietas.

Karakteristik Responden Bedasarkan Komorbiditas Ansietas

Karakteristik responden menurut tipe epilepsi Pada Tabel 2 didapakan tipe epilepsi yang terbanyak mengalami ansietas adalah epilepsi tipe parsial yaitu 7 responden $(16,6 \%)$ dari 9 responden $(21,4 \%)$.

Hasil penelitian ini serupa dengan penelitian sebelumnya yang dilakukan di Serbia pada Tahun 2010 oleh Nenadović1 et al yaitu ditemukan total skor ansietas lebih tinggi pada pasien dengan epilepsi extratemporal $(15,86 \%)$ dan temporal $(15,90 \%)$. Hal ini terkait dengan adanya peran struktur Amigdala yang terletak pada lobus temporal yang terlibat dalam memori, emosi dan ketakutan ikut serta menyebabkan gejala ansietas dan pelepasan epileptik pada epilepsi lobus temporal. Amigdala bertanggung jawab dalam memproseskan dan menyampaikan rangsangan emosional dari banyak sumber ke limbik. Oleh karena itu, amigdale adalah pusat untuk membangkitkan afek, autonomik, 
kognitif, dan komponen endokrin dari gejala ansietas.

Karakteristik responden menurut usia

Menurut kelompok usia, yang paling banyak mengalami ansietas adalah kelompok usia 17 - 25 tahun yaitu 5 responden $(11,8 \%)$ dapat dilihat pada Tabel 2.

Penelitian yang dilakukan di London pada Tahun 1998 oleh Ettinger et al, ditemukan frekuensi ansietas lebih tinggi pada usia remaja yaitu sebesar $16 \%$. Hal serupa juga ditemukan pada penelitian di Irbid pada Tahun 2000 oleh Alwash et al, ansietas pada remaja sebesar 48,5\%. Remaja dengan epilepsi mempunyai risiko lebih tinggi mengalami ansietas daripada anak-anak yang lebih muda. Remaja memiliki kapasitas kognitif yang lebih besar daripada anak-anak untuk memahami dan mempertanyakan sifat tak terduga dan kurang terkontrol dari serangan. Hal ini dapat berpotensi menyebabkan ansietas dan berkontribusi terhadap respon emosional negatif.

Terlebih lagi, dengan tuntutan sosial yang signifikan dan tantangan masa remaja. Hubungan kawan sebaya menjadi pusat pada pengalaman masa remaja dan risiko mengalami serangan di sekolah atau dalam suatu kegiatan sosial bersama teman-teman merupakan ancaman yang berat terhadap kemampuan seorang remaja yang menderita epilepsi untuk berhasil mencapai masaperkembangan pada usia ini oleh sebab itu dapat menjadi masalah yang bermakna yaitu berupa rasa rendah diri, stigmatisasi oleh masyarakat sekitar, dan penolakan sosial yang dialami penderita, sehingga mengakibatkan meningkatnya kemungkinan ansietas dalam berbagai bentuk.

Karakteristik responden menurut jenis kelamin

Pada Tabel 2 menurut jenis kelamin yang lebih banyak mengalami ansietas yaitu kelompok perempuan sebanyak 6 responden $(14,2 \%)$.

Serupa dengan penelitian yang dilakukan di Cyprus pada Tahun 2012 oleh Stavrinides et al, ditemukan frekuensi ansietas lebih tinggi pada perempuan yaitu sebesar 45,79\%. Hal ini sesuai dengan teori bahwa pada pasien epilepsi, ansietas pada perempuan lebih besar daripada laki-laki, karena terkait dengan perubahan hormon menstruasi pada wanita yang memperburuk frekuensi serangan sehingga wanita sering mengalami ansietas.

Selain itu, adapun konflik yang terjadi sebelumnya di kota Ambon dapat mempengaruhi ansietas pada masyarakat Ambon yang dikenal dengan sebutan Gangguan Stres Pasca Trauma (Post Traumatic Stress Disorders; PSTD) yaitu gangguan psikologis setelah mengalami peristiwa traumatik atau stres berat seperti peristiwa perang. Kasus PSTD ini lebih sering http://ojs3.unpatti.ac.id/index.php/moluccamed 
dijumpai pada wanita dibanding pria.

Walaupun sedikit berbeda dengan beberapa penelitian sebelumnya seperti yang dilakukan di Gaza pada Tahun 2013 oleh Ghaith, tidak ditemukan perbedaan yang bermakna. Kemudian yang dilakukan di Surakarta pada Tahun 2012 oleh Anggraeni, tidak ditemukan perbedaan yang bermakna antara perempuan dan laki-laki.

Karakteristik responden menurut pendidikan

Pada Tabel 2 menurut pendidikan, didapatkan kelompok tamatan SMA banyak mengalami ansietas yaitu sebanyak 6 responden $(14,2 \%)$.

Serupa dengan penelitian sebelumnya yang dilakukan di Cyprus pada Tahun 2012 oleh Stavrinides et al, ditemukan pada kelompok tingkat pendidikan menengah mempunyai frekuensi ansietas lebih tinggi yaitu $42,42 \%$. Kemudian hasil yang serupa juga pada penelitian yang dilakukan di Gaza pada Tahun 2013 oleh Ghaith, didapatkan frekuensi ansietas lebih tinggi pada pendidikan tingkat menengah yaitu $38,66 \%$. Tingkat pendidikan mempengaruhi kognitif seseorang. Individu dengan kognitif yang lebih baik dapat mengetahui dan memahami mengenai kondisi penyakitnya sehingga dapat berpotensi menimbulkan kecemasan akan penyakitnya. Seperti yang dijelaskan oleh Pulver dan Kanner, bahwa selain ansietas merupakan gangguan psikiatri yang disebabkan oleh epilepsi, ansietas juga dapat timbul sebagai respon dari seseorang yang mengetahui bahwa dirinya terdiagnosis epilepsi.

Karakteristik responden menurut pekerjaan Menurut pekerjaan pada Tabel 2 ditemukan responden yang banyak mengalami ansietas adalah kelompok yang tidak bekerja yaitu sebanyak 7 responden $(16,6 \%)$.

Hasil penelitian yang dilakukan di Gaza pada Tahun 2013 oleh Ghaith, didapatkan ansietas sebesar $34,33 \%$ pada kelompok tidak bekerja. Hal ini terjadi karena pada pengangguran biasanya menyebabkan rendah diri, berkurangnya kesejahteraan dan kualitas hidup yang rendah sehingga dapat memicu terjadinya ansietas. Berbeda dengan penelitian yang dilakukan di Surakarta pada Tahun 2012 oleh Anggraeni, tidak ditemukan perbedaan yang bermakna. pada kelompok pekerjaan.

\section{Kesimpulan}

Berdasarkan hasil penelitian yang telah dibahas, maka pada penelitian ini dapat dibuat beberapa kesimpulan sebagai berikut:

1. Proporsi ansietas pada pasien epilepsi primer periode Juli - Oktober 2013 di Ambon adalah sebesar 21,4\%.

2. Dari proporsi ansietas tersebut ditemukan derajat ansietas yang paling banyak 
adalah ansietas derajat ringan yaitu sebesar $11,8 \%$.

3. Karakteristik responden berdasarkan derajat ansietas adalah sebagai berikut:

a. Tipe epilepsi yang paling banyak mengalami ansietas adalah epilepsi tipe parsial yaitu sebesar 16,6\%.

b. Usia yang paling banyak mengalami ansietas adalah usia 17 - 25 tahun yaitu sebesar $11,8 \%$.

c. Jenis kelamin yang terbanyak mengalami ansietas adalah perempuan yaitu sebesar $14,2 \%$.

d. Berdasarkan pendidikan, ansietas terbanyak pada lulusan SMA yaitu sebesar $14,2 \%$.

e. Berdasarkan pekerjaan, ansietas dialami terbanyak pada kelompok yang tidak bekerja yaitu sebesar $16,6 \%$.

\section{Referensi}

1. Mardjono M, Sidharta P. Neurologi klinis dasar. Jakarta: Dian Rakyat; 2010. Hal.439

2. Neligan A, Sander JW. The incidence and prevalence of epilepsy [Internet]. London: UCL Institute of Neurology; 2011 [cited 2012 December 30];[7p]. Available from: URL:

http://www.epilepsysociety.org.uk/FileSto rage/main_content/01-the-incidence-andprevalence-of-epilepsy.pdf

3. Purba JS. Epilepsi: permasalahan di reseptor atau neurotransmitter. Medicinus. 2008;21(4):99-100.

4. Mac TL, Tran DS, Quet F, Odermatt P, Preux PM, Tan CT. Epidemiology, aetiology, and clinical management of epilepsy in Asia: a systematic review. Lancet Neural. 2007;6:533-43.

5. Sander JW. The epidemiology of epilepsy revisited. Curr Opin Neurol. 2003;16(2):165-70.

6. Sander JW, Shorvon SD. Epidemiology of the epilepsies. J Neurol Neurosurg Psychiatry. 1996;61:433-43.

7. Hawari I. Epilepsi di Indonesia [internet]. Jakarta: Yayasan Epilepsi Indonesia; 2010 Agustus [cited 2013 Maret 25]. Available from: URL: $\quad$ http://www.inaepsy.org/2010/08/epilepsi-diindonesia.html

8. Putri MA. Prevalensi epilepsi di poliklinik saraf RSUP Fatmawati Jakarta pada tahun 2004 - 2008. [skripsi]. Jakarta: Universitas Islam Negeri; 2009.

9. Ekinci O. Anxiety disorders in epilepsy. In: Szirmai A, editor. Anxiety and Related Disorders. Turkey: InTech; 2011.p.217-26.

10. Beyenburg S, Mitchell AJ, Schmidt D, Elger CE, Reuber M. Anxiety in patients with epilepsy: systematic review and suggestions for clinical management. Epilepsy and Behavior. 2005;7:161-71.

11. Gaitatzis A, Carroll K, Majeed A, Sander JW. The epidemiology of the comorbidity of epilepsy in the general population. Epilepsia. 2004;45(12):1613-22.

12. Harsono. The psychiatric perspectives of epilepsy. Maj Kedokt Indon. 2008 April;58(4):123-9.

13. Anggraeni LP. Hubungan antara kecemasan dengan frekuensi bangkitan pada penderita epilepsy parsial di RSUD dr. Moewardi. [skripsi]. Surakarta: Universitas Sebelas Maret; 2012.

14. Mudjaddid E. Pemahaman dan penanganan psikosomatik gangguan ansietas dan depresi di bidang ilmu penyakit dalam. Edisi 2. Jakarta: Pusat Penerbitan Departemen Ilmu Penyakit Dalam Fakultas Kedokteran Universitas Indonesia; 2006.

15. Kamus bahasa Indonesia. Edisi 16. Jakarta: Pusat Bahasa; 2008. Karakteristik; hal.639.

16. Chaplin JP. Kamus lengkap psikologi. Jakarta: PT. Raja Grafindo Prasada; 2008. Karakteristik; hal.421. 
17. Titlic M, Basic S, Hajnsek S, Lusic I. Comorbidity psychiatric disorders in epilepsy: a review of literature. Bratisl Lek Listy. 2009;110(2):105-9.

18. World Health Organization. Epilepsy: historical overview [internet]. 1997 [cited 2013 Maret 25]. Avaliable form: URL: http://www.who.int/inf-is/en/fact 168.html

19. Fisher RS, Boas WE, Blume W, Elger C, Genton P, Lee P, et al. Epileptic seizures and epilepsy: definition proposed by the International League Against Epilepsy (ILAE) and the International Bureau for Epilepsy (IBE). Epilepsia. 2005;46(4):4702.

20. Nurviana EV, Siswati, Dewi KS. Penerimaan diri pada penderita epilepsi. [skripsi]. Jakarta: Universitas Diponegoro; 2008.

21. Aylward R. Epilepsy. J.R. Coll Physicians Edinb. 2006;36:326-31. Causes of epilepsy [internet]. England: National Health Service; 2012 Sept 6 [cited 2013 Maret 25]. Available from: URL: http://www.nhs.uk/Conditions/Epilepsy/P ages/Causes.aspx

22. Lombardo MC. Gangguan kejang. Dalam: Price SA, Wilson LM, editor. Patofisiologi: konsep klinis proses-proses penyakit. Edisi 6. Vol 2. Jakarta: EGC; 2005. Hal.1157-59.

23. Herman B, Seidenberg M, Jones J. The neurobehavioural comorbidities of epilepsy: can a natural history be developed. Lancet Neural. 2008 Feb;7:151-60.

24. Hernandez-Frau PE. Psychiatric disorders associated with epilepsy [Internet]. America: American Academy of Neurology; 2011 June 8 [cited 2012 December 30]. Available from:
URL:

http://emedicine.medscape.com/article/1 186336-overview\#aw2aab6b8

25. Seidenberg M, Pulsipher DT, Hermann B. Association of epilepsy and comorbid condition. Future Neurol. 2009 Sept 1;4(5):663-8.

26. Huberty TJ. Anxiety and anxiety disorders in children: information for parents [Internet]. Bethesda: National Association of School Psychologists; 2000 [cited 2013 Maret 25]. Available from:

URL:

http://www.nasponline.org/resources/int online/anxiety_huberty.pdf

27. Anxiety disorders [Internet]. Columbia: University of Missouri; 2001 [cited 2013 Maret 25]. Available from:

URL:

http://dps.missouri.edu/resources/Handb ook/anxiety.pdf

28. Kaplan HI, Saddock BJ. Sinopsis psikiatri. Edisi 8. Jakarta: Bina Rupa Aksara; 2005. Hal.557-62.

29. Anxiety disorders [Internet]. Canada: The Human Face of Mental Health Illness; 2012 April 18 [cited 2012 December 30];[8p]. Available from:

URL: $\quad$ http://www.phacaspc.gc.ca/publicat/humanhumain06/pdf/human_face_e.pdf

30. Roca C. Anxiety disorders [Internet]. Bethesda: National Institute of Mental Health; 2010 April 15 [cited 2012 December 30];[8p]. Available from:URL:http://www.centerforplain language.org/downloads/clearmark2011/ WomensHealth_Anxiety_Disorders.pdf 